Supplement of Nat. Hazards Earth Syst. Sci., 21, 1051-1069, 2021

https://doi.org/10.5194/nhess-21-1051-2021-supplement

(C) Author(s) 2021. CC BY 4.0 License.

(c) (1)

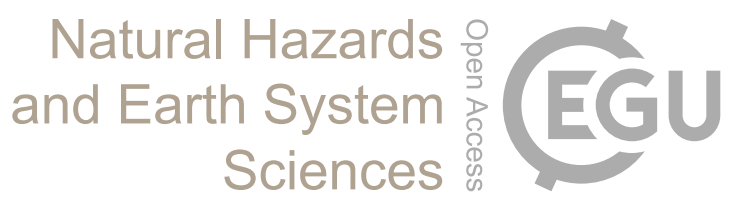

Supplement of

\title{
Wet and dry spells in Senegal: comparison of detection based on satellite products, reanalysis, and in situ estimates
}

Cheikh Modou Noreyni Fall et al.

Correspondence to: Cheikh Modou Noreyni Fall (noreyni27@gmail.com)

The copyright of individual parts of the supplement might differ from the article licence. 


\section{${ }_{11}$ Additional Figures}

12 Supplementary figures were included to provide additional informations on

13 others dry and wet spell indicators beyond what was pratical in the main 14 article.

15 variogram

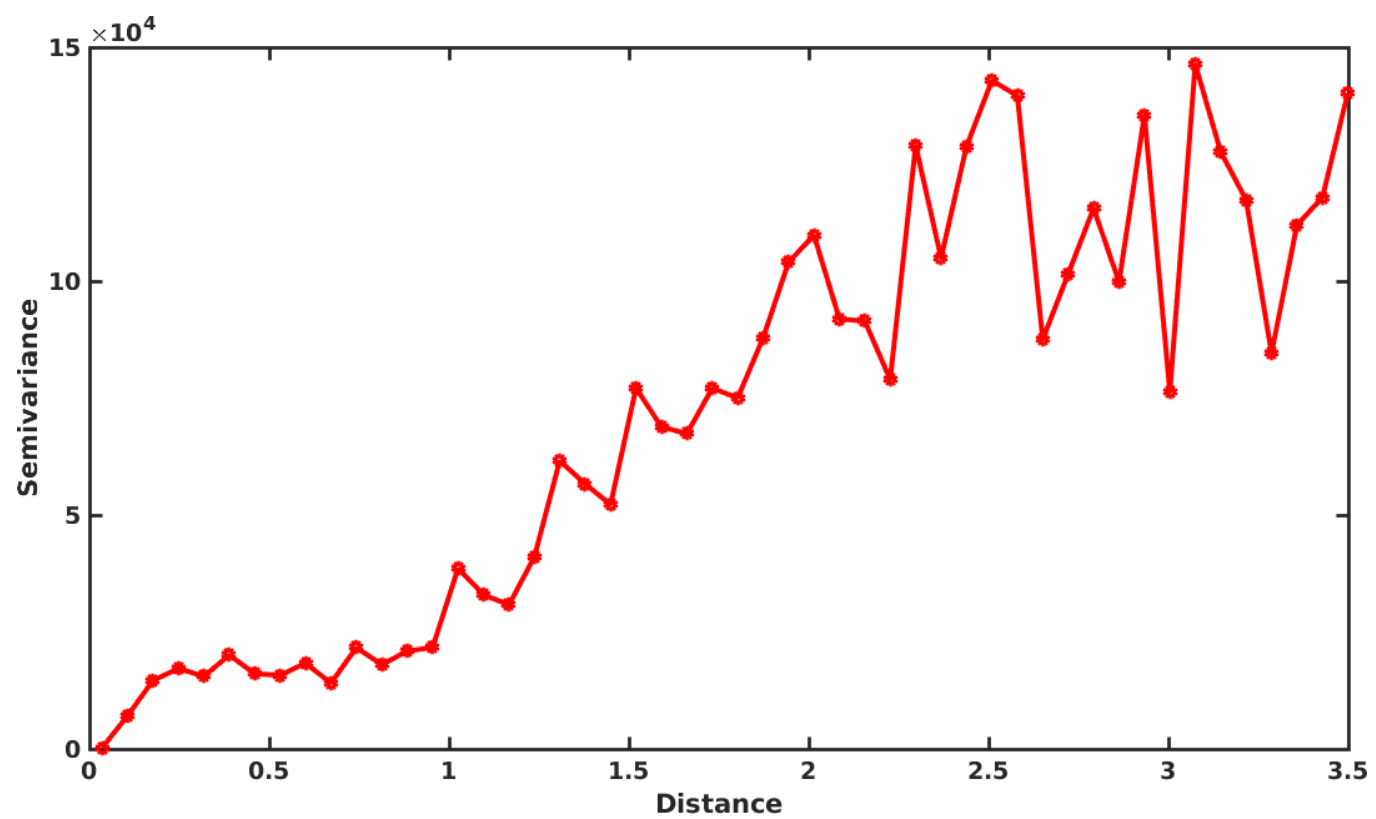

Figure S1: Climatological rainfall amount variogram computed from the gaugedata from June to October. 


\section{${ }_{16}$ Dry Spells}
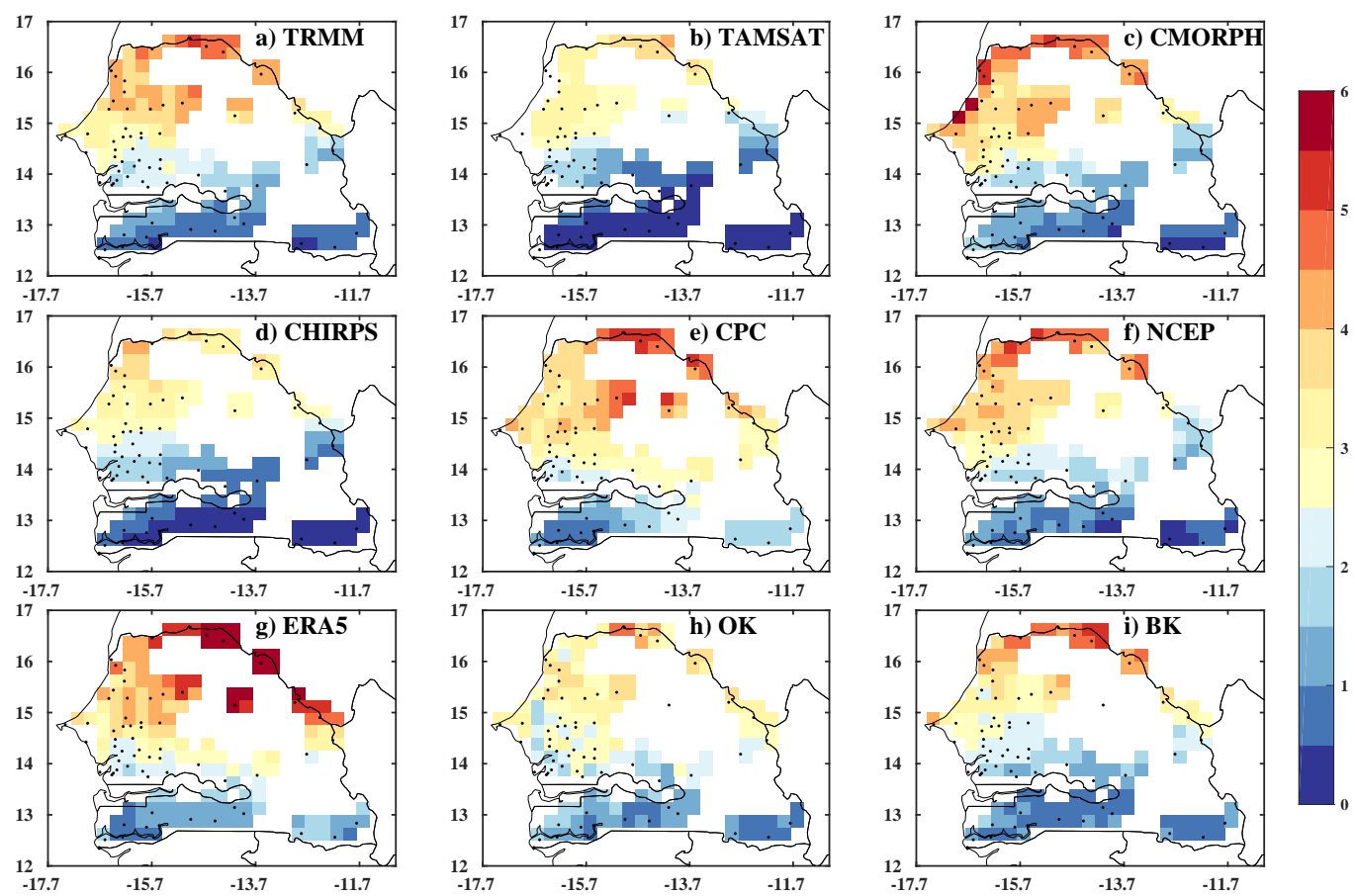

Figure S2: Spatial distribution of the number of DSC10 computed in the rainyseason (June to October) for the overlap period (1998-2010) for : a) TRMM, b) TAMSAT, c) CMORPH, d) CHIRPS, e) CPC, f) NCEP, g) ERA5, h)OK,i) BK. 



Figure S3: Spatial distribution of the number of DSC20 computed in the rainy season (June to October) for the overlap period (1998-2010) for : a) TRMM,b) TAMSAT, c) CMORPH, d) CHIRPS, e) CPC, f) NCEP, g) ERA5, $\mathrm{OK}, \mathrm{i}) \mathrm{BK}$.

\section{${ }_{17}$ Wet Spells}



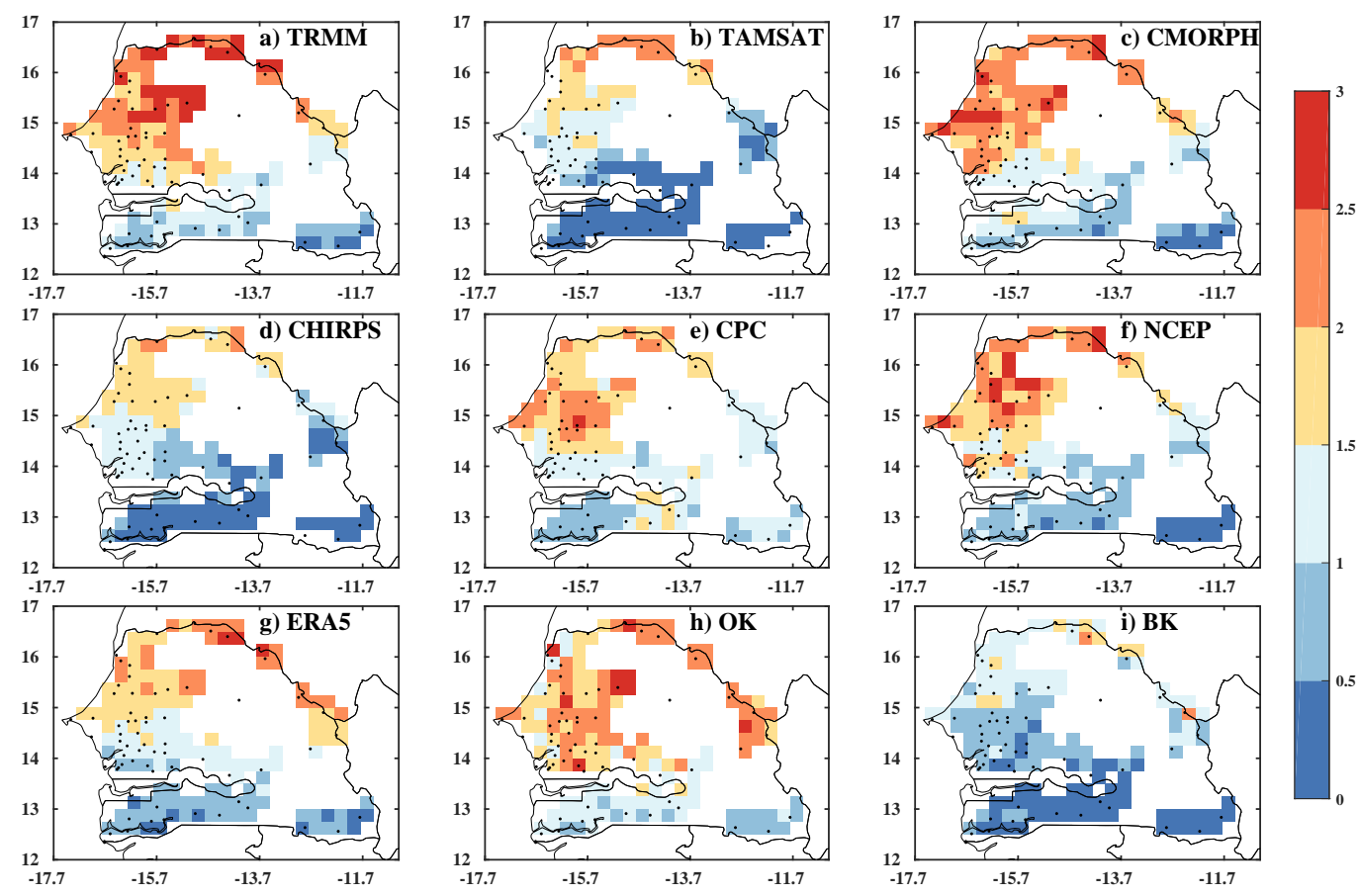

Figure S4: Spatial distribution of the number of DSl computed in the rainy season (June to October) for the overlap period (1998-2010) for : a) TRMM, b) TAMSAT, c) CMORPH, d) CHIRPS, e) CPC, f) NCEP, g) ERA5, h) $\mathrm{OK}, \mathrm{i}) \mathrm{BK}$. 

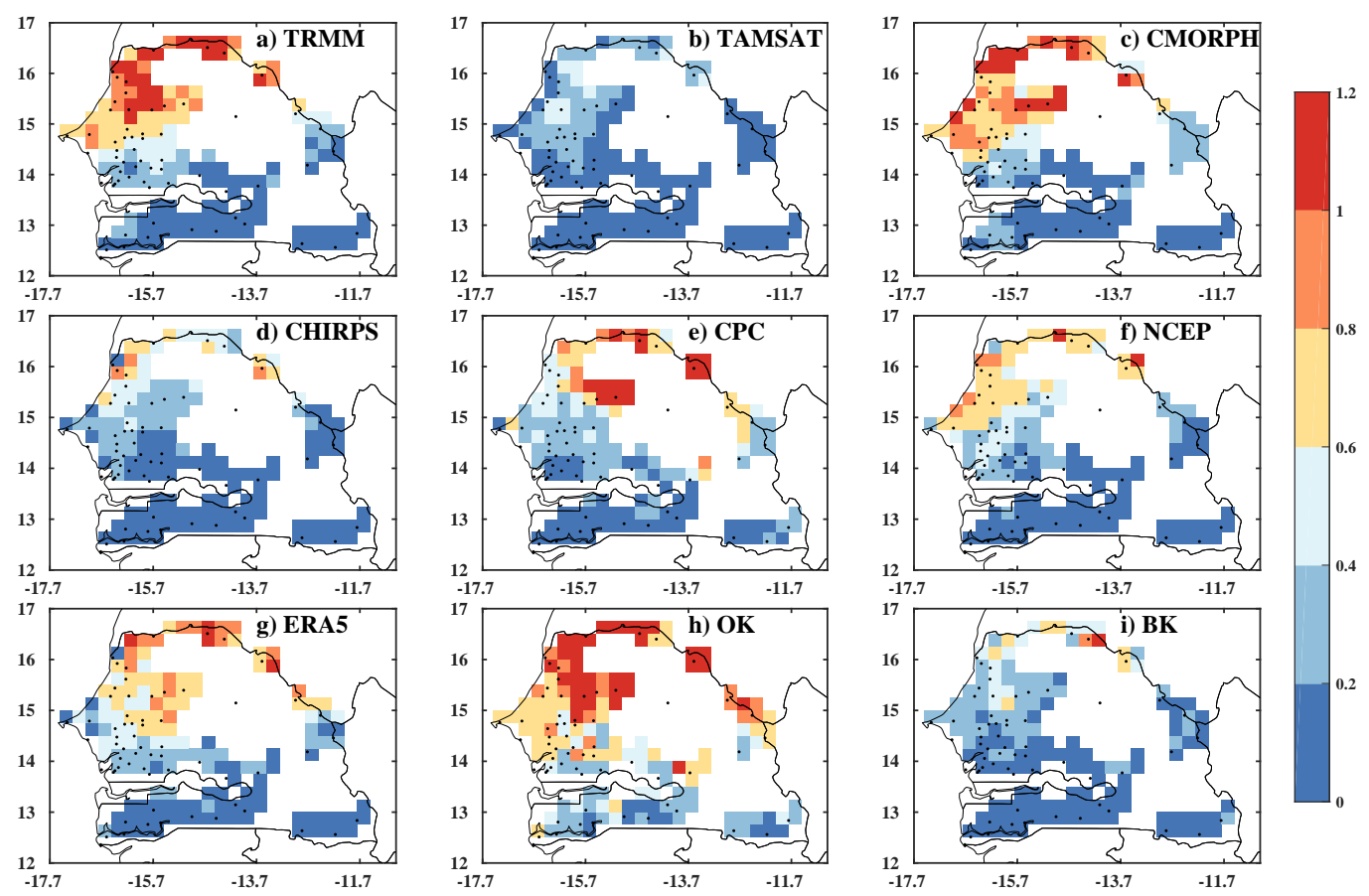

Figure S5: Spatial distribution of the number of DSxl computed in the rainy season (June to October) for the overlap period (1998-2010) for : a) TRMM, b) TAMSAT, c) CMORPH, d) CHIRPS, e) CPC, f) NCEP, g) ERA5, h) $\mathrm{OK}$, i) BK. 

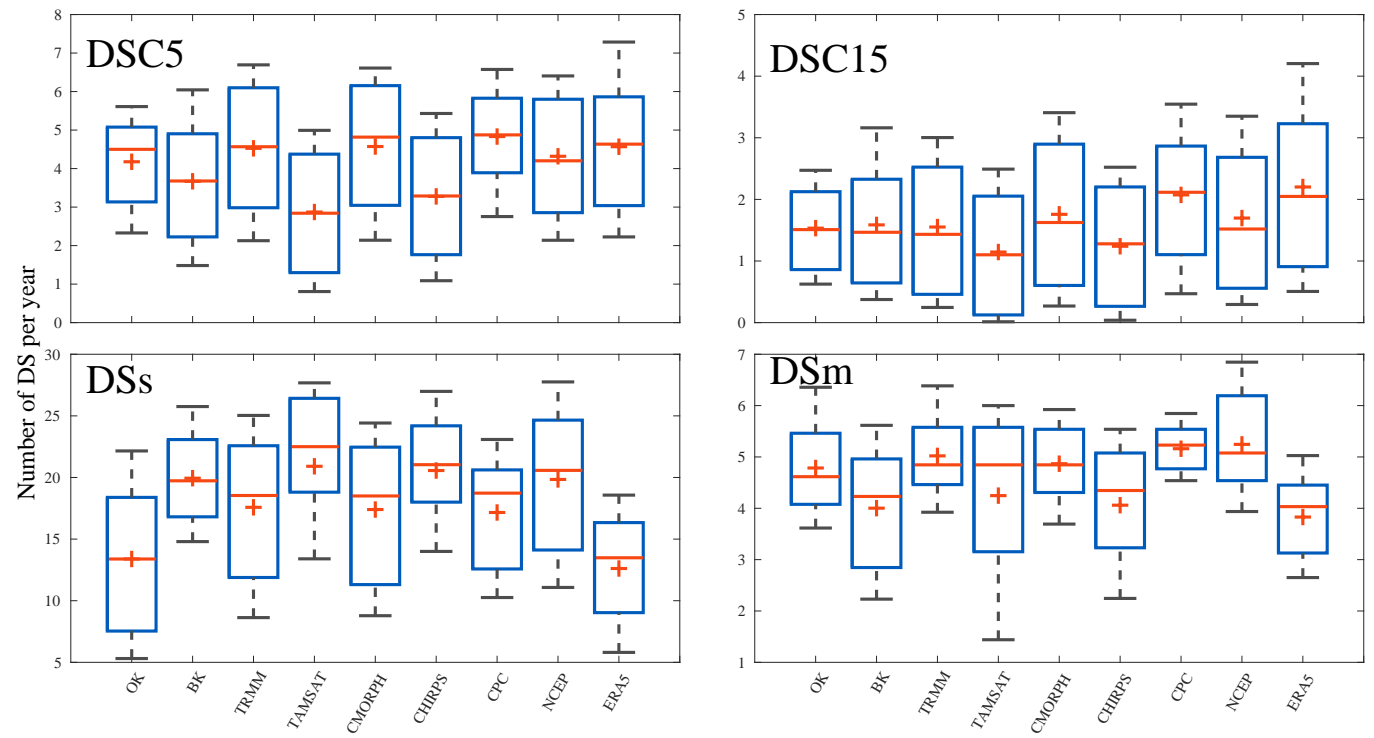

Figure S6: Climatological (1998-2010) distribution of the number of DSC5, DSC15, DSs and DSm for : TRMM, TAMSAT, CMORPH, CHIRPS, CPC, NCEP, ERA5, BK, OK. The + represent the mean value, the - represent the median value, the box represents the 25 th and 75 th percentile values, and the whiskers represent the extreme values. 
Taylor Diagram of DS

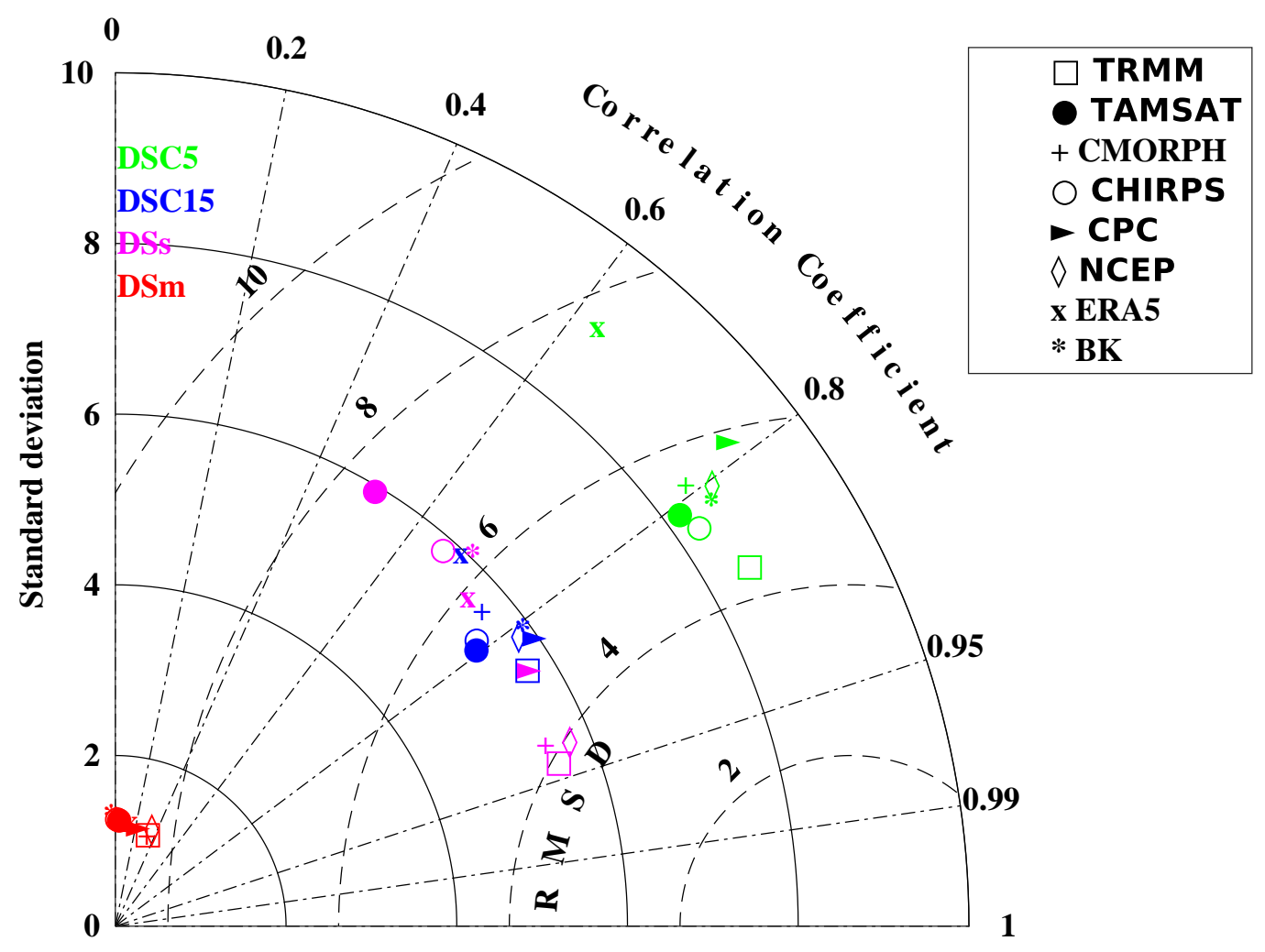

Figure S7: Climatological (1998-2010) distribution of the seasonal distribution of number of DSC5, DSC15, DSs and DSm for : TRMM, TAMSAT, CMORPH, CHIRPS, CPC, NCEP, ERA5, BK, OK. 
Taylor Diagram of DS

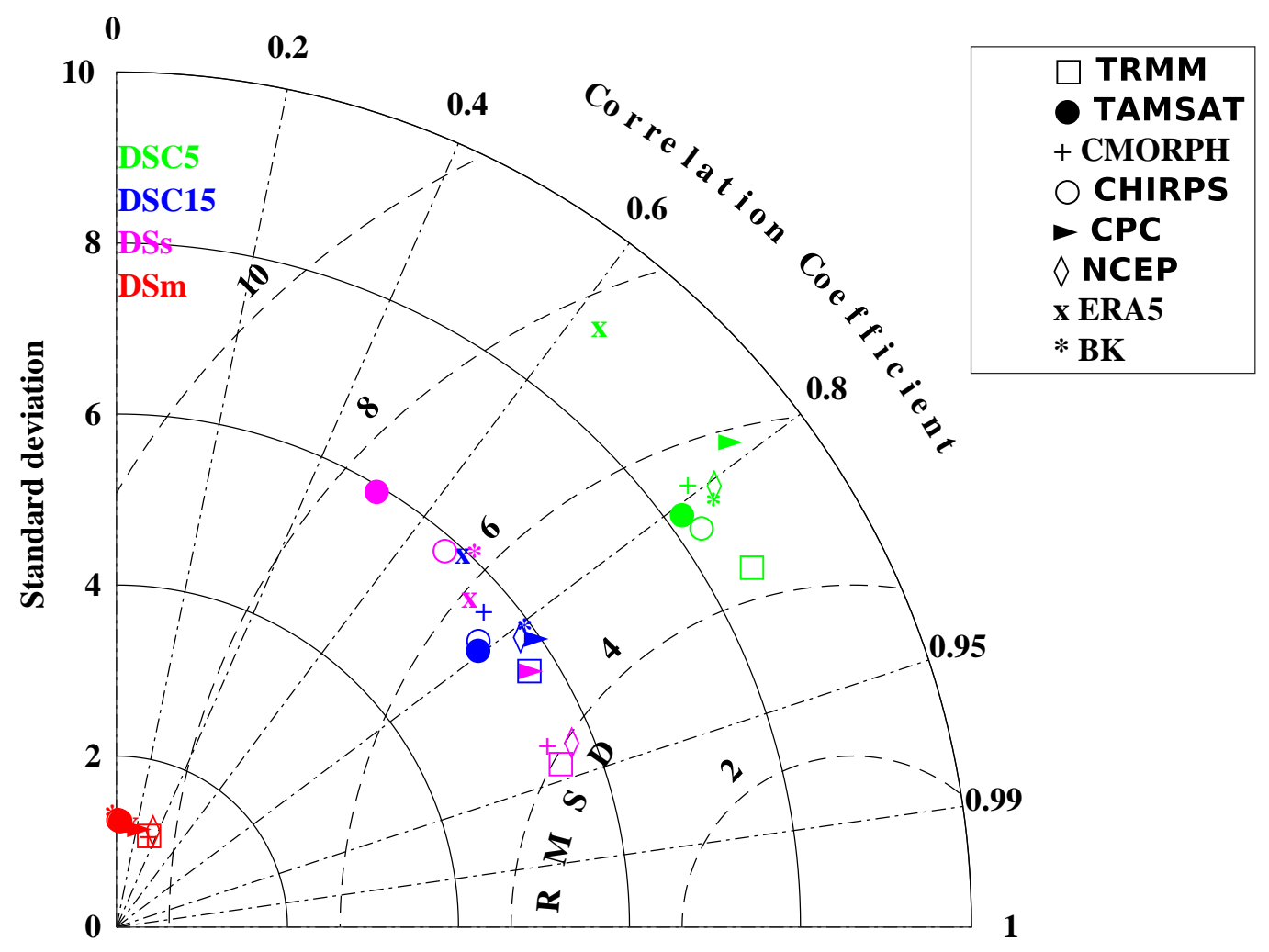

Figure S8: Taylor Diagram of the occurrence of DSC5, DSC15, DSs and DSmfor : TRMM, TAMSAT, CMORPH, CHIRPS, CPC, NCEP, ERA5, $\mathrm{BK}$. OK product is considered as reference 


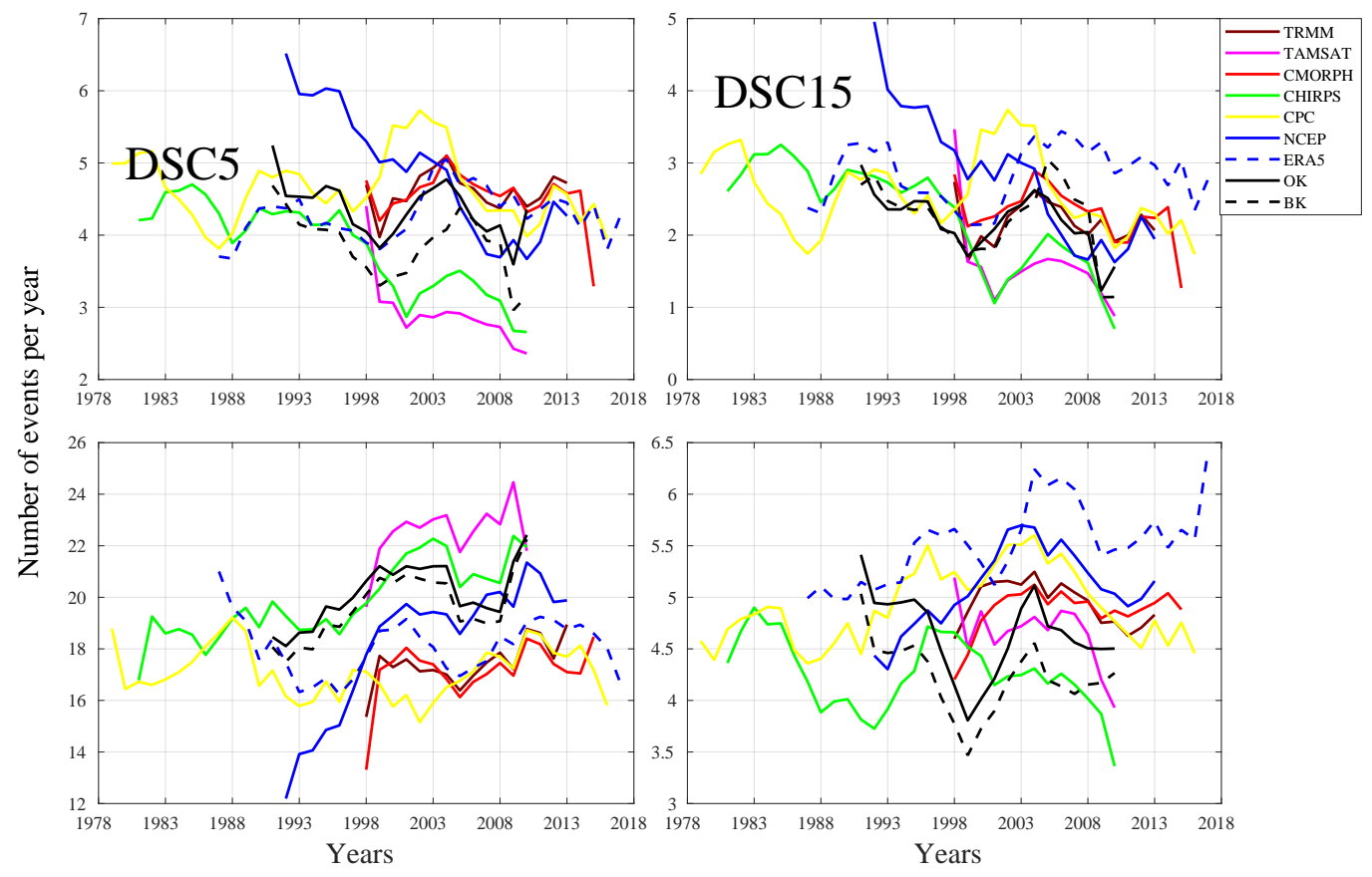

Figure S9: Interannual variability of the occurrence of DSC5, DSC15, DSs and DSm for : TRMM (1998-2013), TAMSAT(1998-2010), CMORPH (19982015), CHIRPS (1981-2010), CPC (1979-2016), NCEP (1992-2013), ERA5 (1987-2017), BK (1991-2010), OK (1991-2010) 

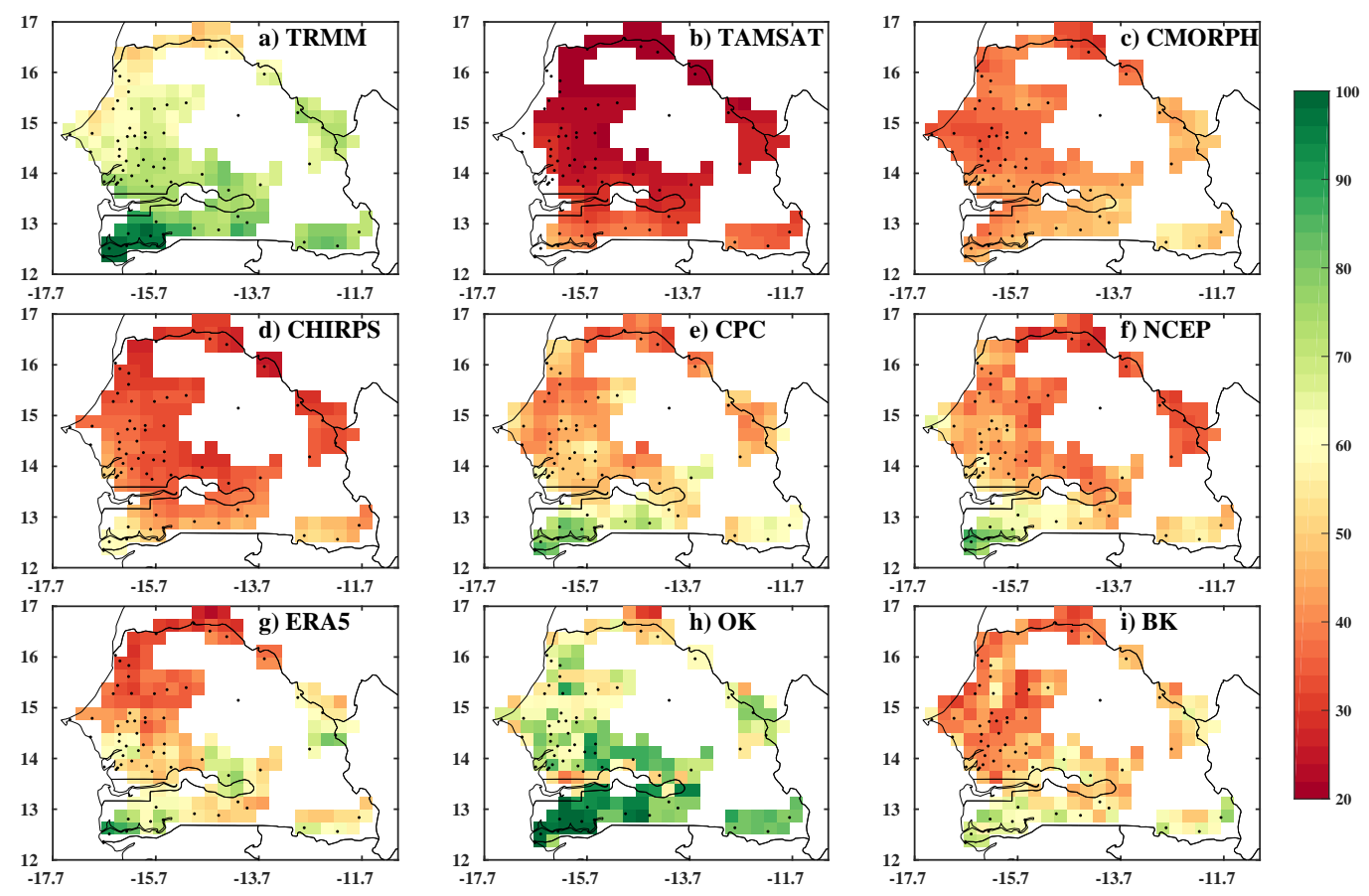

Figure S10: Spatial distribution of the number of WS1 99P computed in the rainy season (June to October) for the overlap period (1998-2010) for : a) TRMM, b) TAMSAT, c) CMORPH, d) CHIRPS, e) CPC, f) NCEP, g) ERA5, h)OK, i) BK. 

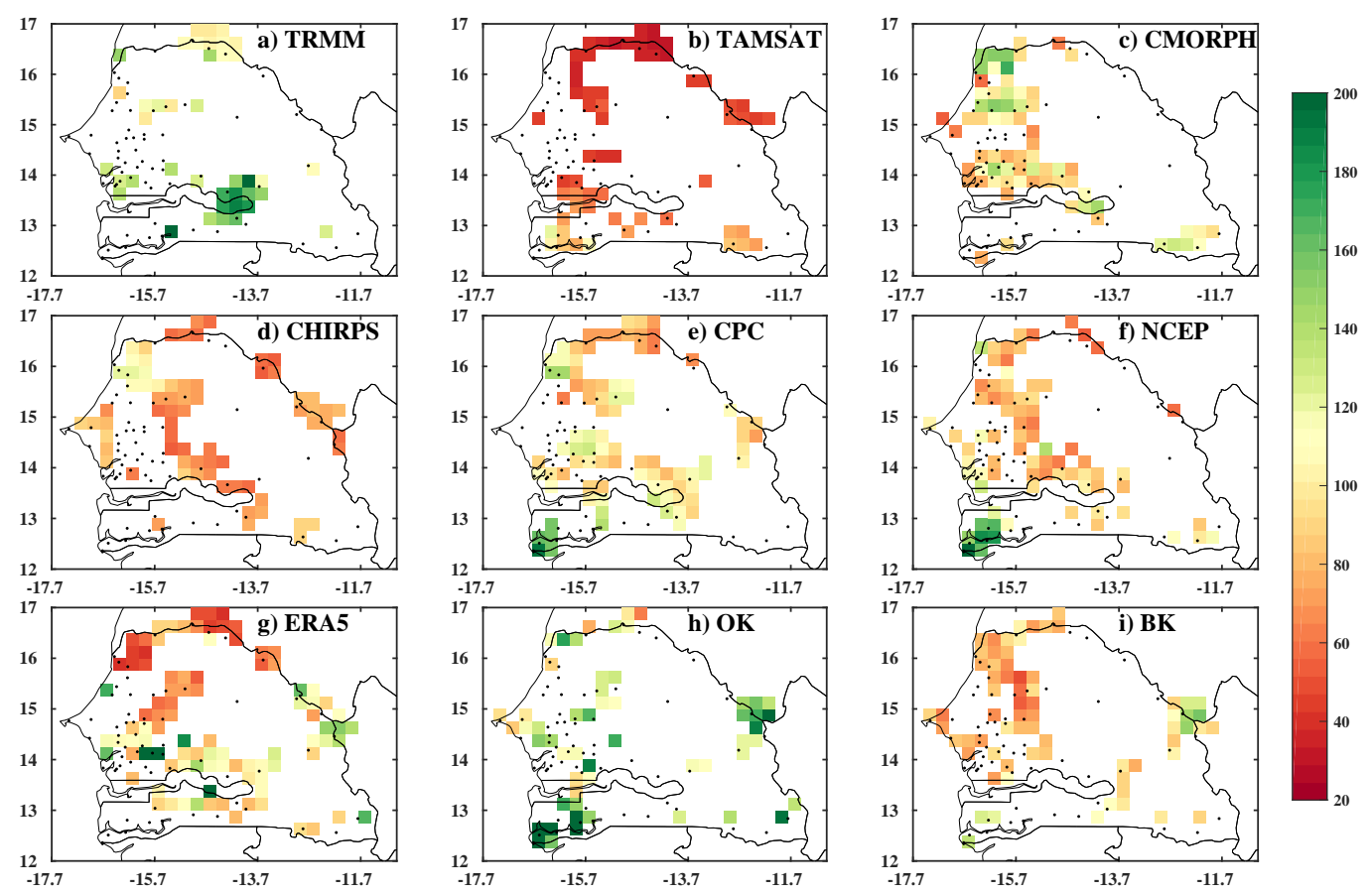

Figure S11: Spatial distribution of the number of WSM 99P computed in the rainy season (June to October) for the overlap period (1998-2010) for : a) TRMM, b) TAMSAT, c) CMORPH, d) CHIRPS, e) CPC, f) NCEP, g) ERA5, h) OK, i) BK. 

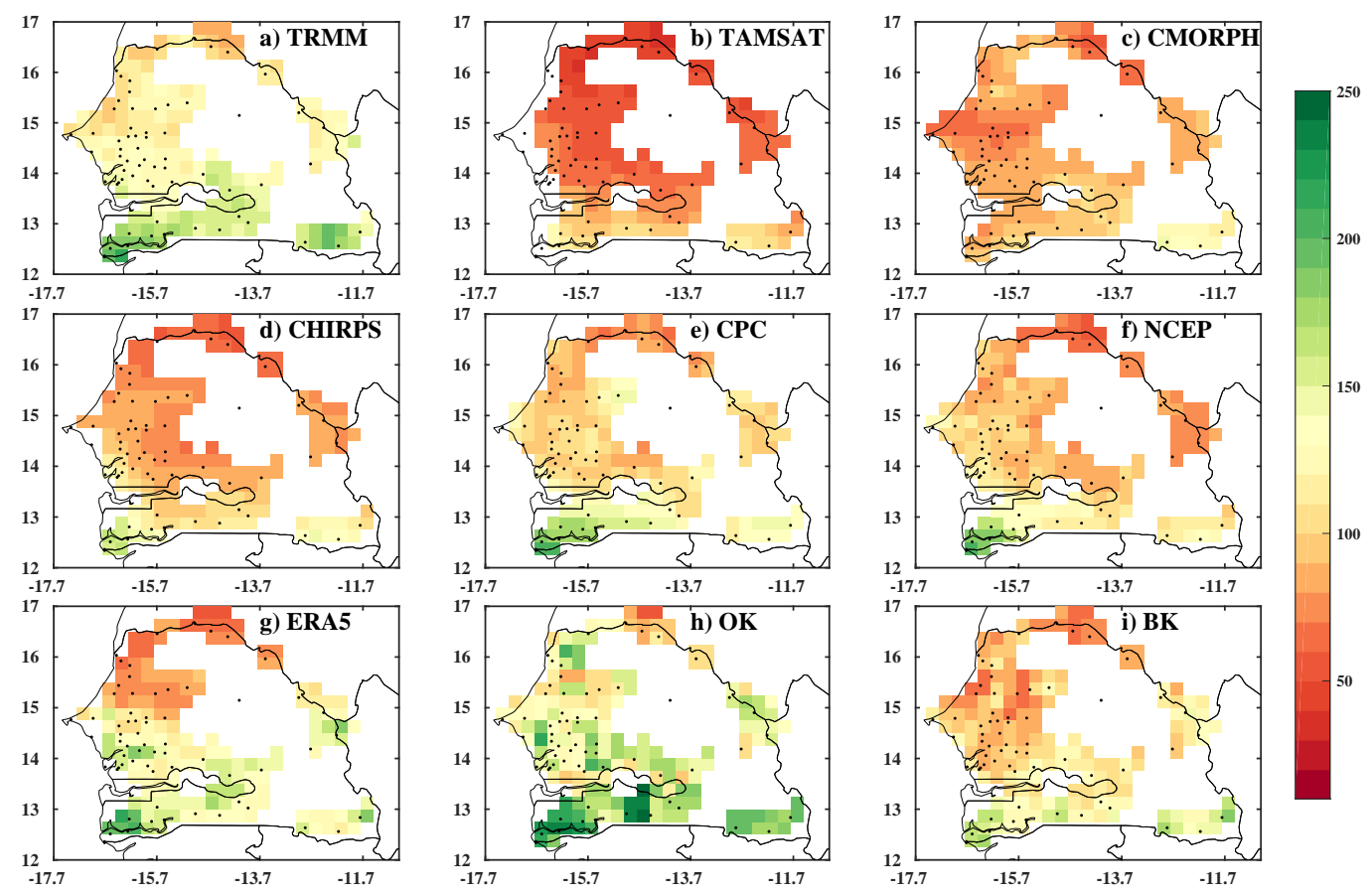

Figure S12: Spatial distribution of the number of WSC5 99P computed in the rainy season (June to October) for the overlap period (1998-2010) for : a) TRMM, b) TAMSAT, c) CMORPH, d) CHIRPS, e) CPC, f) NCEP, g) ERA5, h) OK, i) BK. 

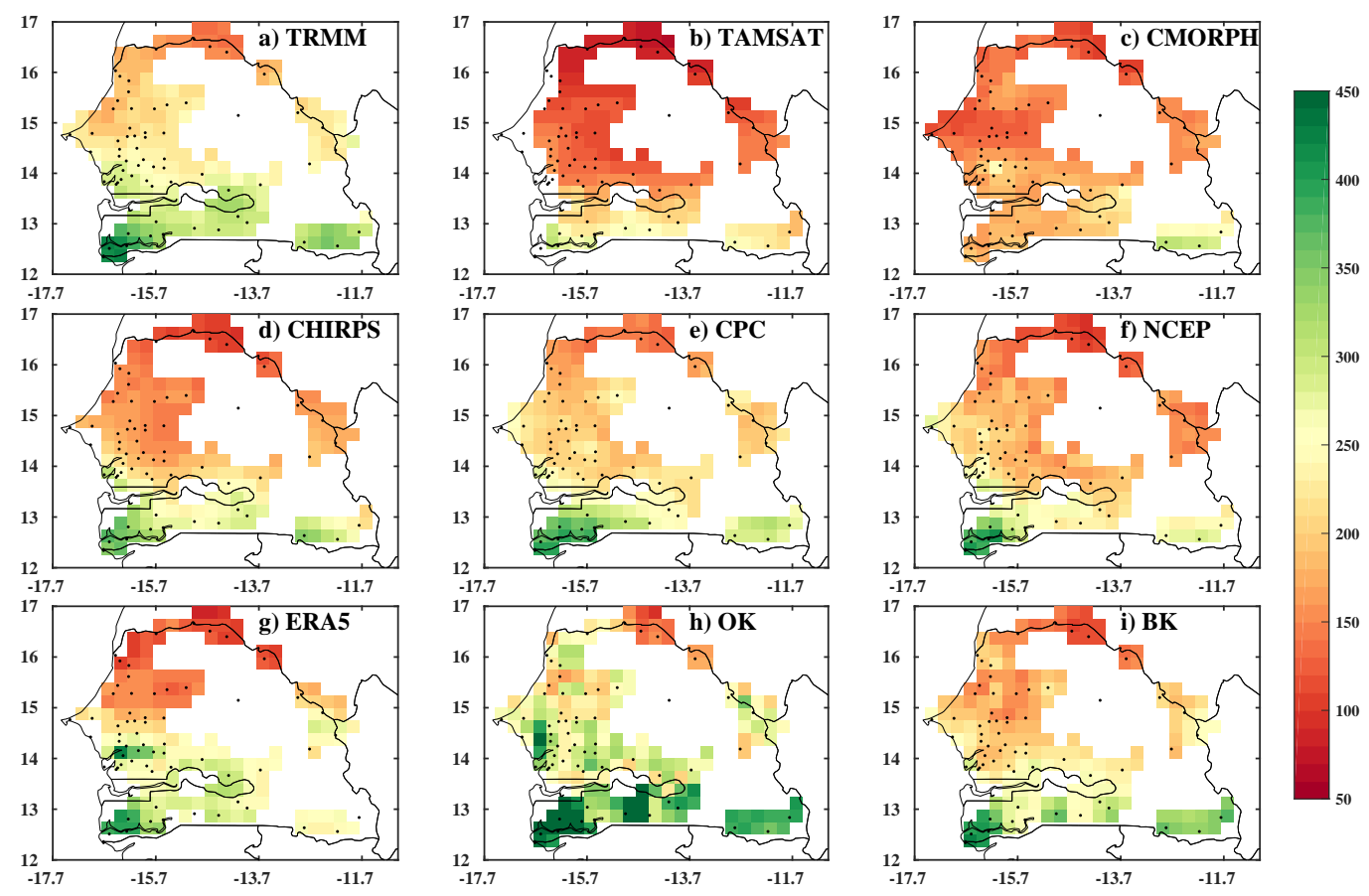

Figure S13: Spatial distribution of the number of WSC15 99P computed in the rainy season (June to October) for the overlap period (1998-2010) for : a) TRMM, b) TAMSAT, c) CMORPH, d) CHIRPS, e) CPC, f) NCEP, g) ERA5, h) OK, i) BK. 


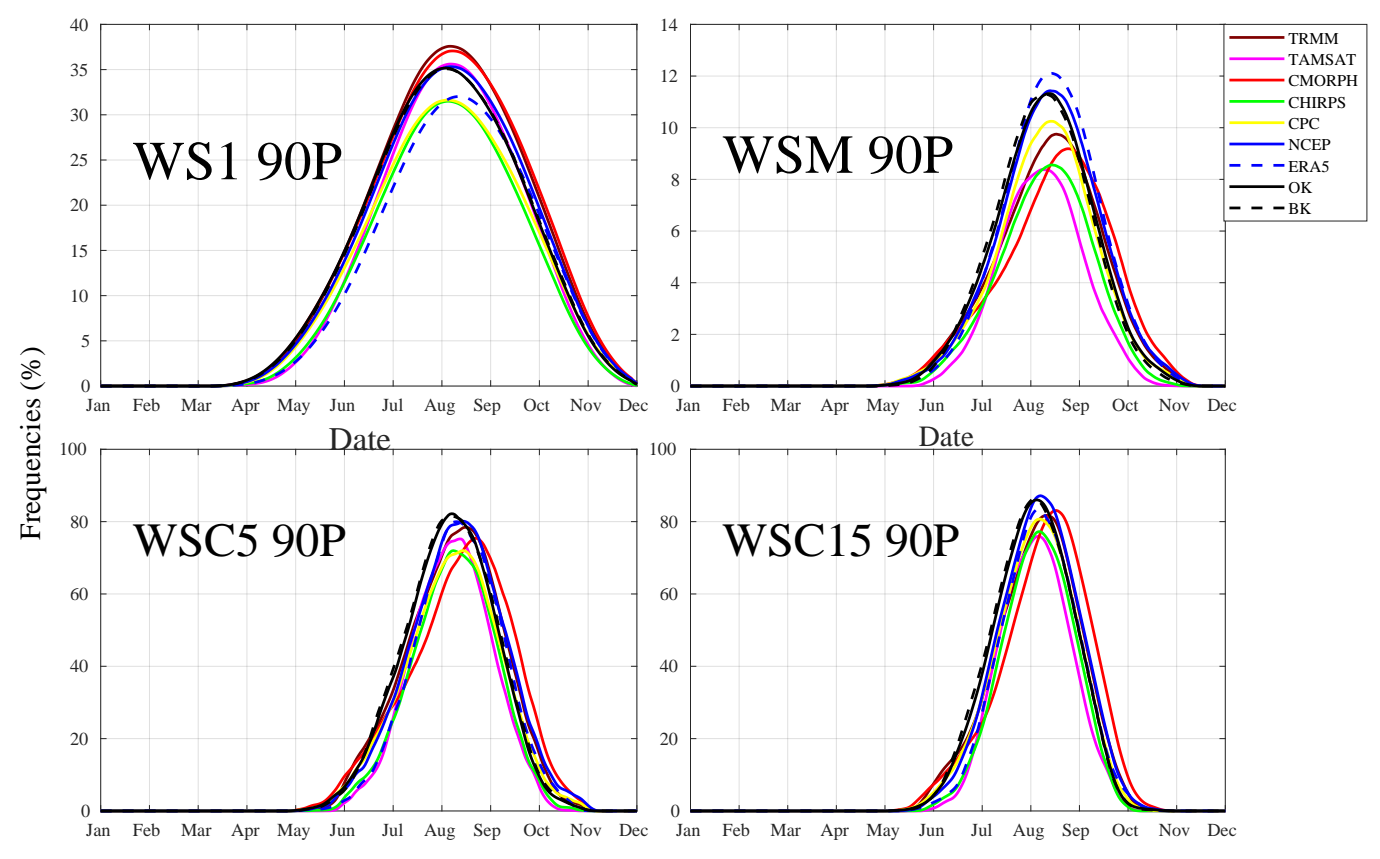

Figure S14: Seasonal cycle of the occurrence of WS1, WSM, WSC5 and WSC15 (90th) percentiles averaged for the period 1998-2010, for TRMM, TAMSAT, CMORPH, CHIRPS, CPC, NCEP, ERA5, BK, OK
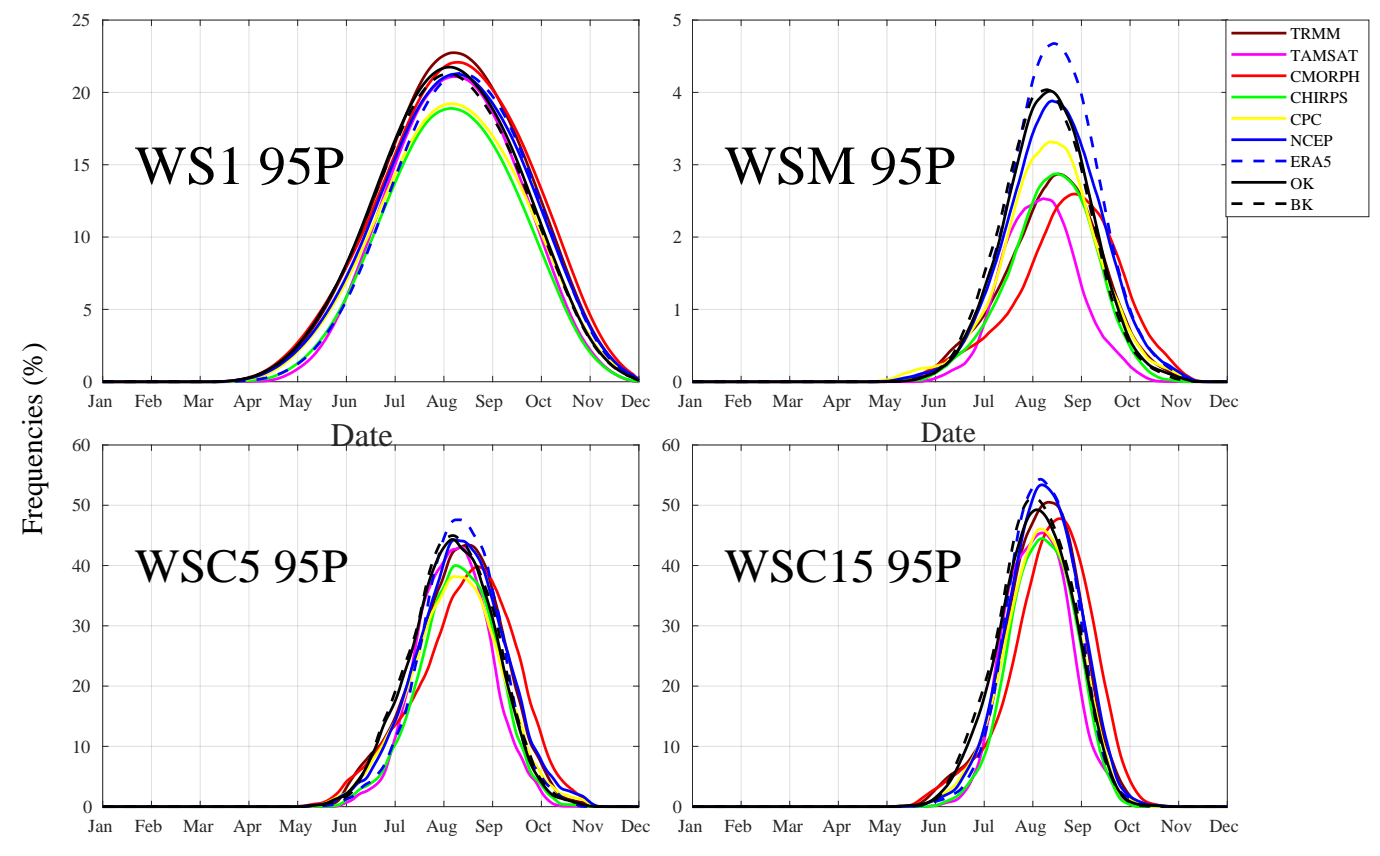

Figure S15: Same as figure S5 for the $95^{\text {th }}$ percentile 


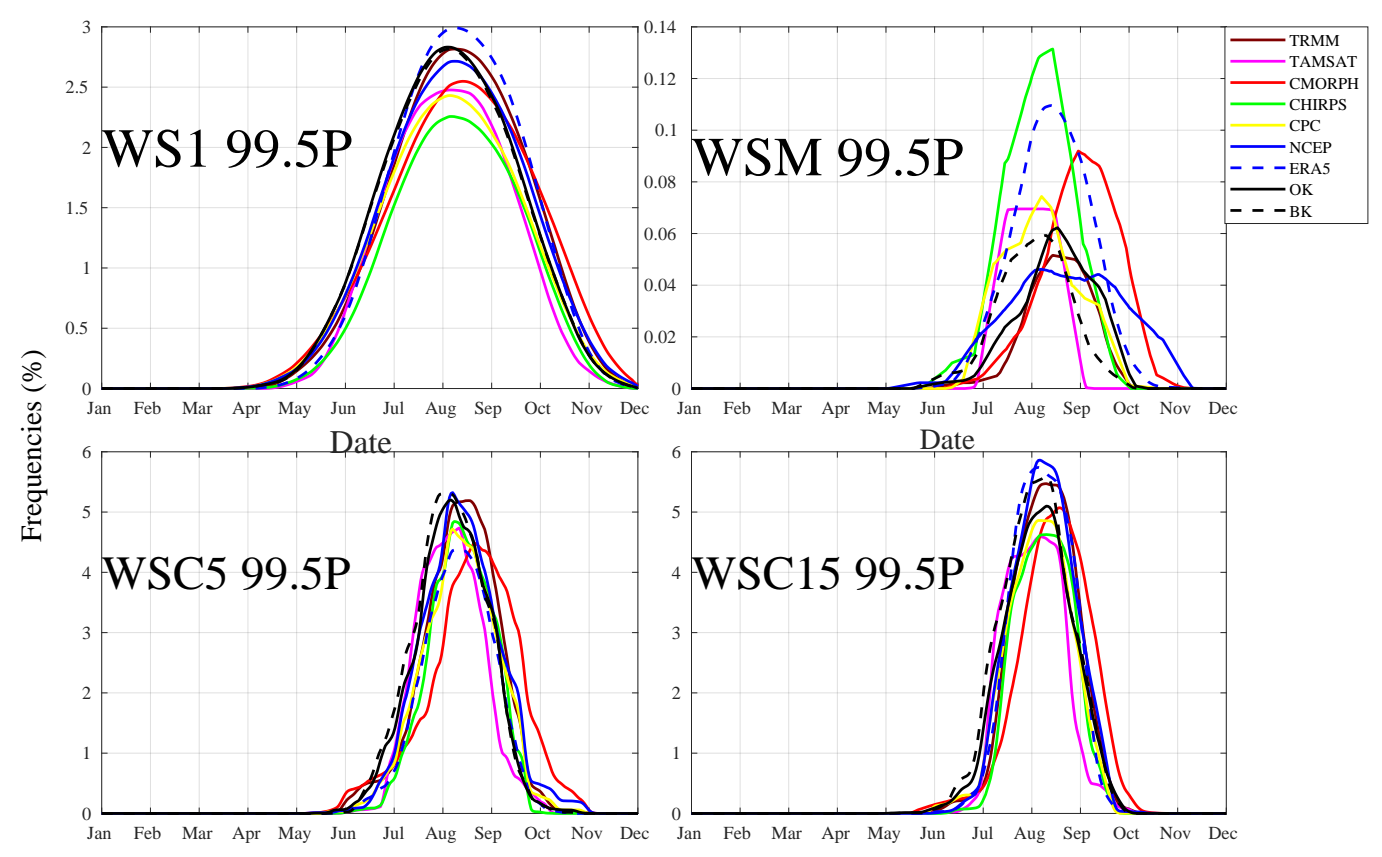

Figure S16: Same as figure S5 for the $99.5^{\text {th }}$ percentile
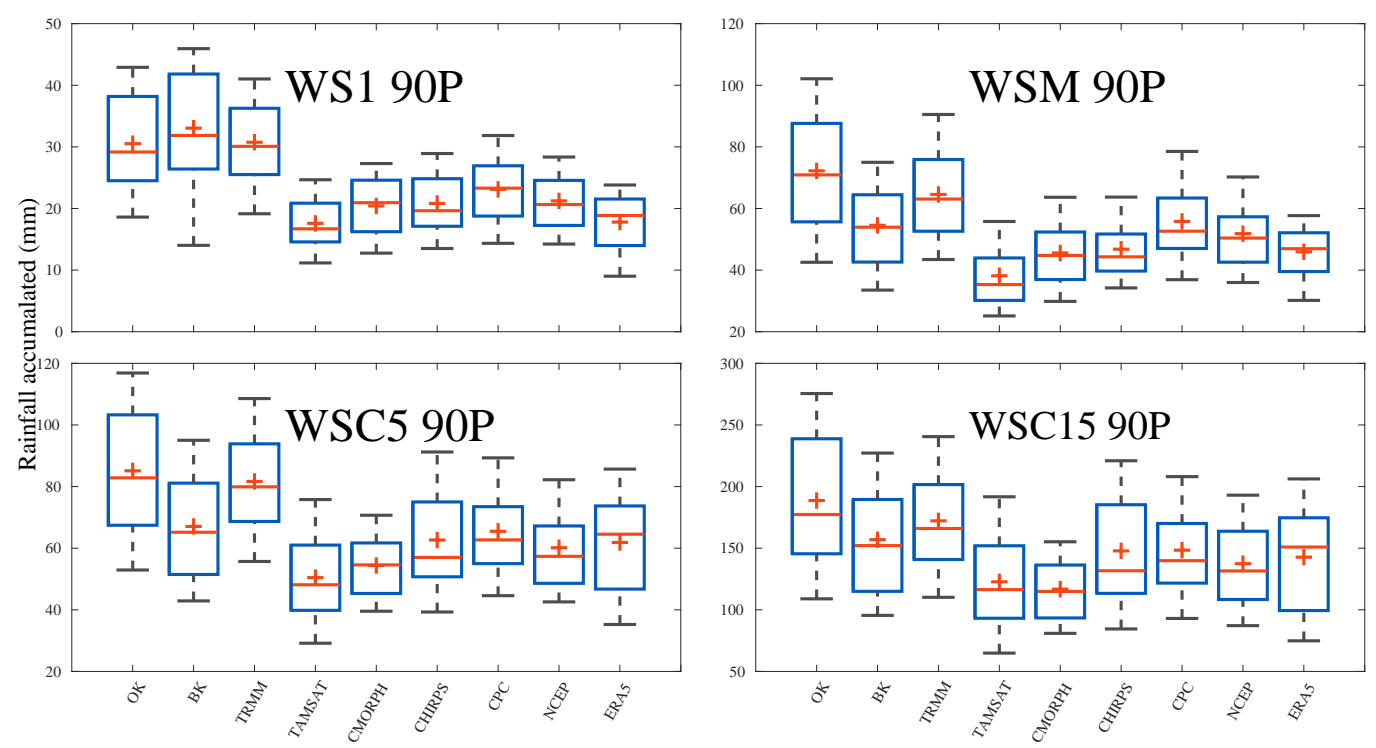

Figure S17: Yearly cumulated rainfall provided by WS1, WSM, WSC5 and WSC15 (90th) percentiles, averaged for the period 1998-2010, for TRMM, TAMSAT, CMORPH, CHIRPS, CPC, NCEP, ERA5, BK, OK. The + represent the mean value, the - represent the median value, the box represents the 25 th and 75 th percentile values, and the whiskers represent the extreme values 

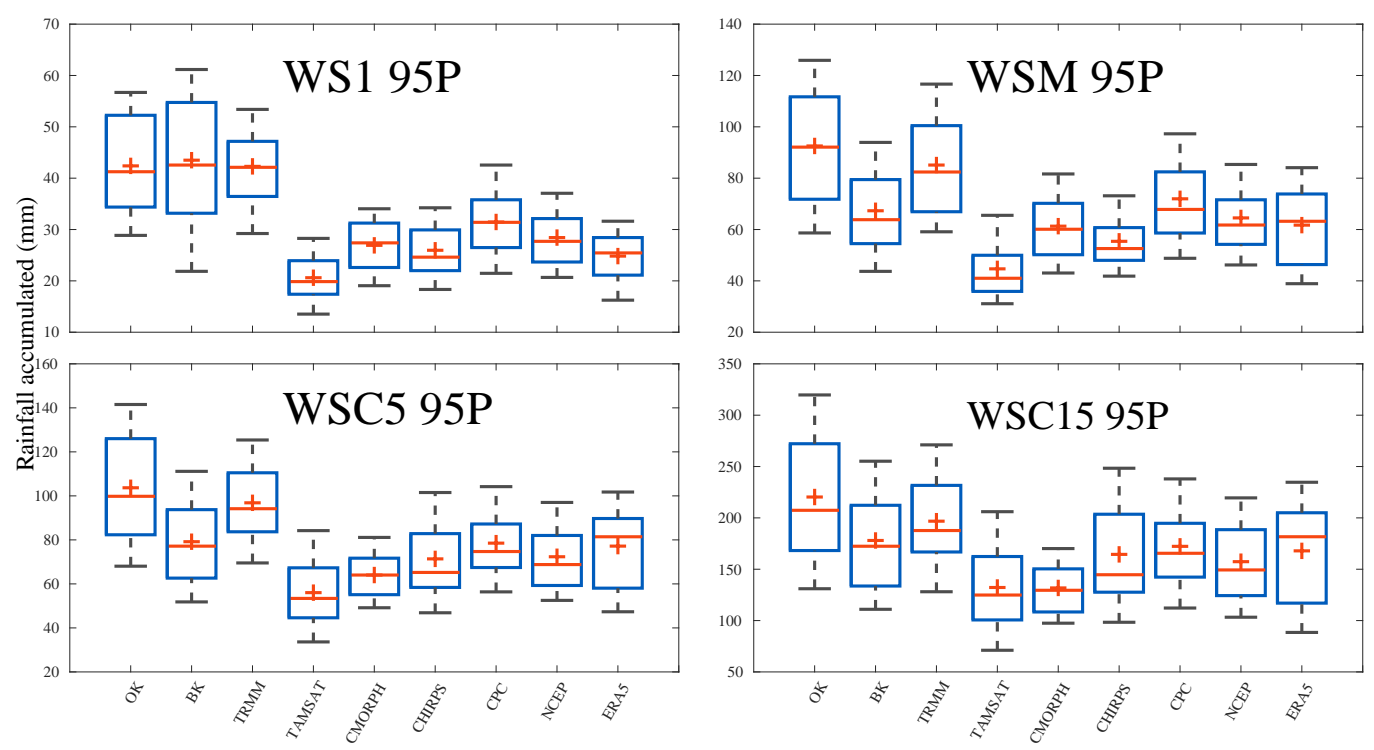

Figure S18: Same as Figure S8 for the $95^{\text {th }}$ percentiles.
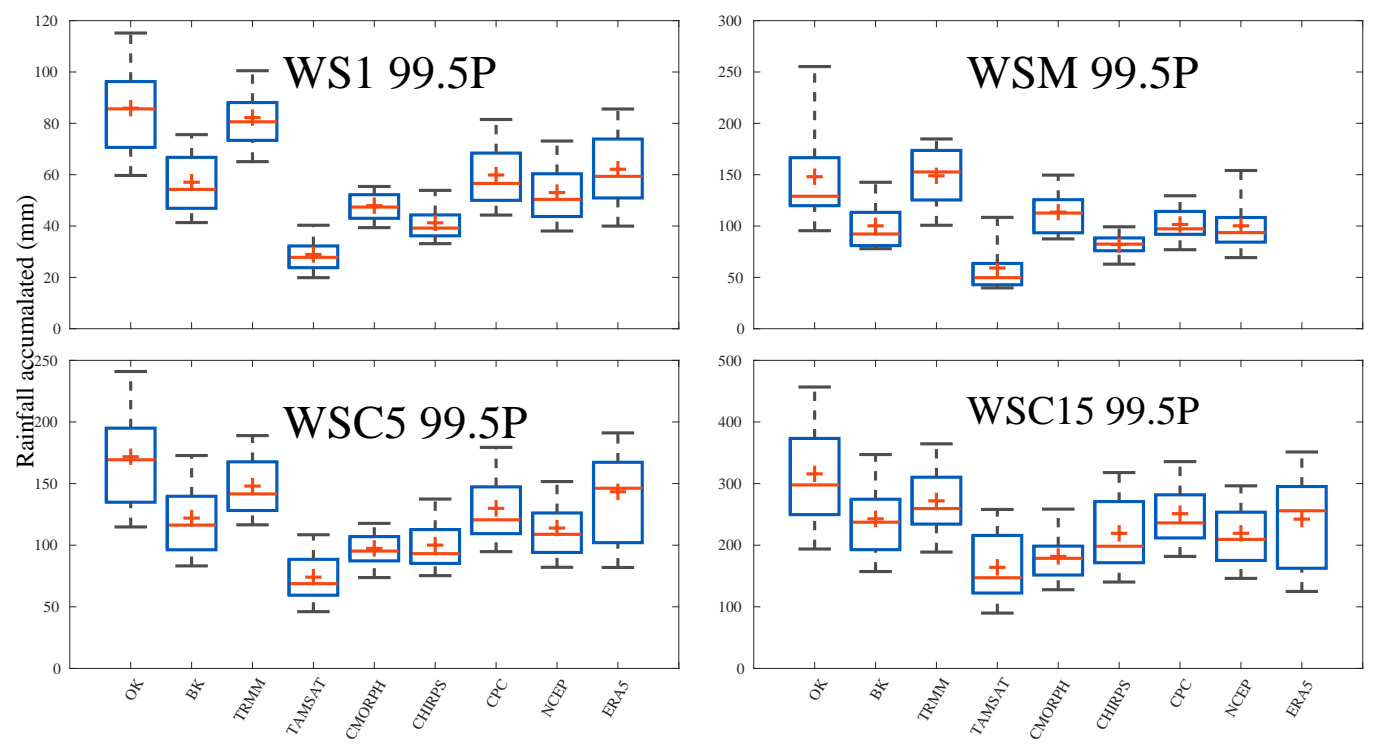

Figure S19: Same as Figure S8 for the $99.5^{\text {th }}$ percentile. 


\section{Taylor Diagram of WS}

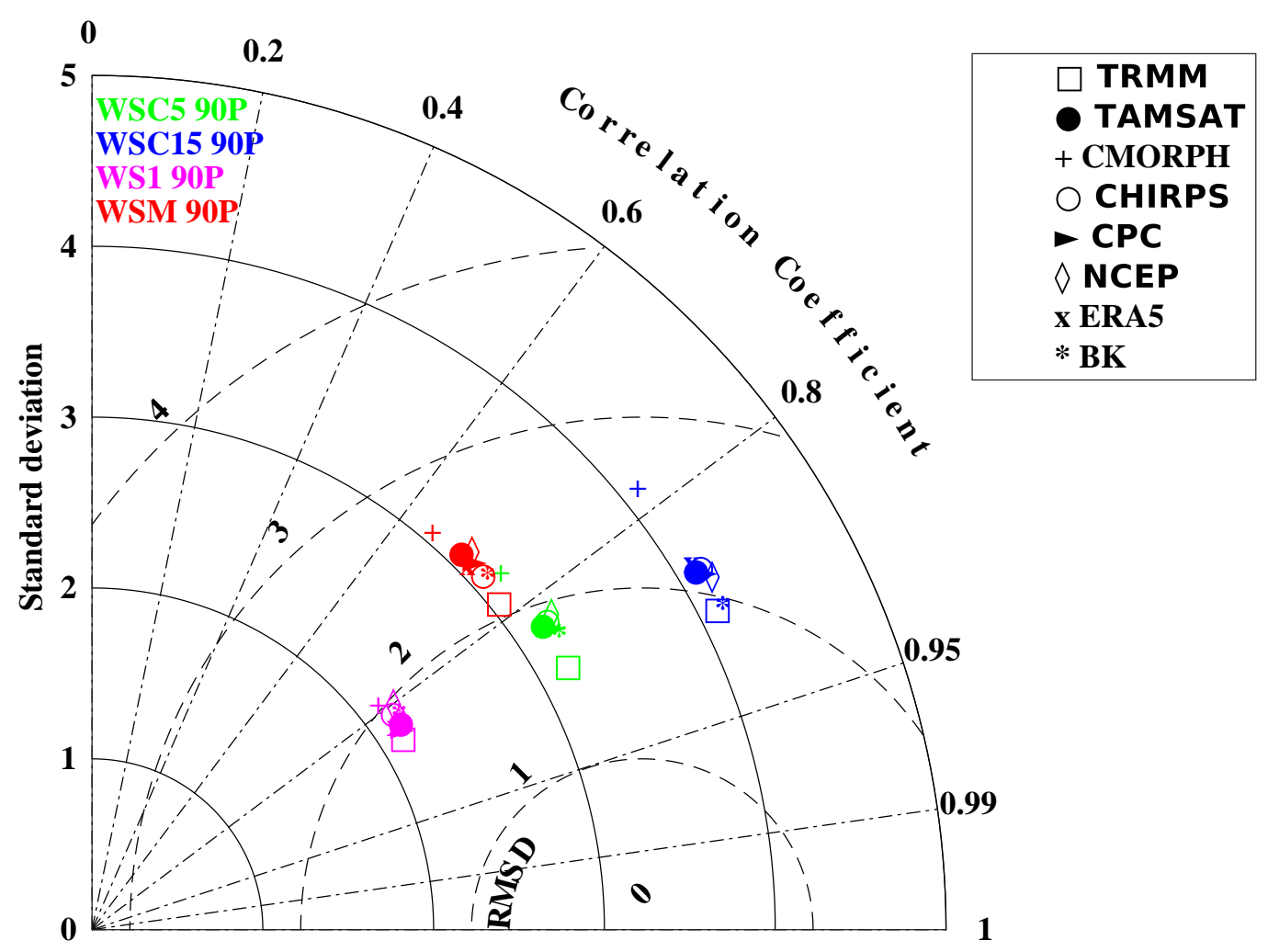

Figure S20: Taylor Diagram of the spatial distribution of the number of WSC5, WS1, WSM, WSC5 and WSC15 (90th) percentiles using TRMM, TAMSAT, CMORPH, CHIRPS, CPC, NCEP, ERA5, BK. OK product is considered asreference during the period 1998-2010 
Taylor Diagram of WS

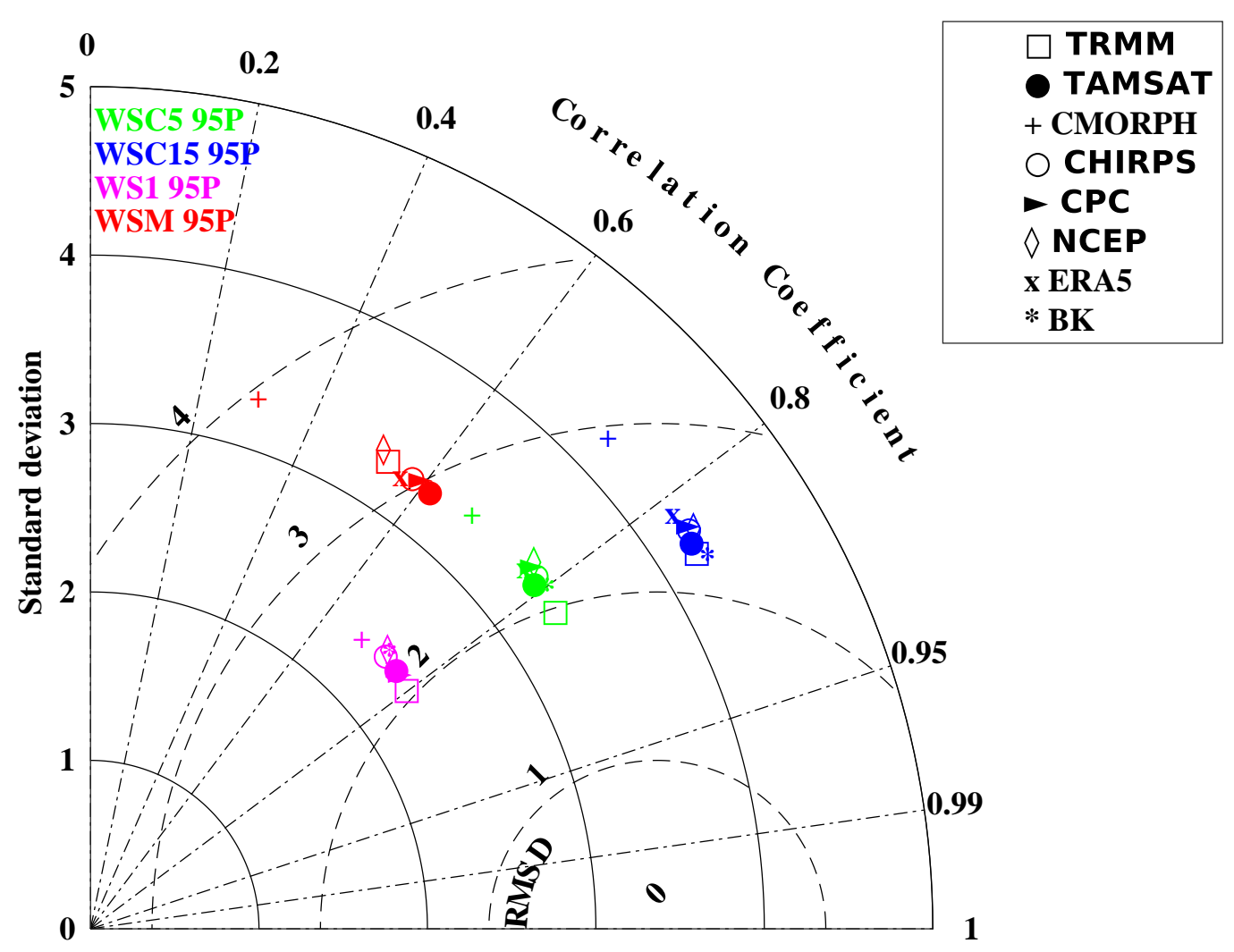

Figure S21: Taylor Diagram of the occurrence of WSC5, WS1, WSM, WSC5 and WSC15 (95th) percentiles using TRMM, TAMSAT, CMORPH, CHIRPS, CPC, NCEP, ERA5, OK. BK product is considered as reference during the period 1998-2010 